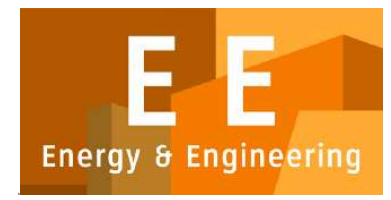

PAPER - OPEN ACCESS

\title{
BONEK sebagai Kearifan Lokal Menuju Tata Ruang yang Inklusif
}

\author{
Author $\quad$ : Rohadatul Aisyi dkk., \\ DOI $\quad: 10.32734 /$ ee.v3i1.867 \\ Electronic ISSN : :2654-704X \\ Print ISSN : $2654-7031$
}

Volume 3 Issue 1 - 2020 TALENTA Conference Series: Energy \& Engineering (EE)

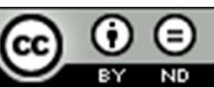

This work is licensed under a Creative Commons Attribution-NoDerivatives 4.0 International License.

Published under licence by TALENTA Publisher, Universitas Sumatera Utara

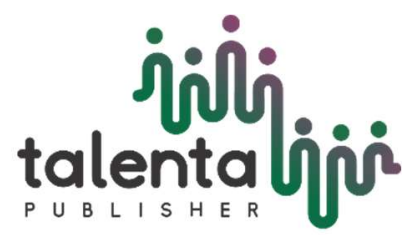




\title{
BONEK sebagai Kearifan Lokal Menuju Tata Ruang yang Inklusif BONEK as Local Wisdom Towards Inclusive Spatial Planning
}

\author{
Rohadatul Aisyi ${ }^{1}$, Alwiyah Maulidiyah ${ }^{1}$, Sawitri Retno Haudiati ${ }^{1}$, Fadhilah Ramadhani ${ }^{1}$, \\ Nadiah Irbah Rosyadah ${ }^{1}$ \\ ${ }^{1}$ Universitas Diponegoro, Yayasan Peduli Kasih Anak Berkebutuhan Khusus
}

rohadatulaisyi198@gmail.com, alwiyahm@gmail.com, fadhilahramadhani1992@gmail.com,nadiahirbahrosyadah@gmail.com, nunuksrh@gmail.com

\begin{abstract}
Abstrak
Makalah ini mencoba menerapkan kearifan lokal sebagai yang tidak selalu terkait masa lalu maupun tatanan masyarakat adat. Kearifan lokal seharusnya bisa terdapat pada masa kini dan menjadi identitas suatu komunitas modern (perkotaan). Kearifan lokal diperlukan bukan hanya agar masyarakat tersebut bertahan terhadap gempuran budaya luar, namun juga diharapkan dapat menyelesaikan berbagai permasalahan, termasuk masalah Anak Berkebutuhan Khusus (ABK). Bonek - singkatan dari kata bondho nekat, arti sebenarnya : hanya berbekal kenekatan (berani). Namun nekat yang diartikan positif, yaitu sebagai suatu keyakinan dalam melakukan tindakan, sepanjang memperjuangkan kebenaran, pasti mewujud. Oleh karena itu bonek perlu diasosiasikan dengan karakter pantang menyerah dan terlebih bila dikaitkan dengan sejarah kepahlawanan Surabaya, bonek adalah nilai egaliter, solider, pekerja keras, namun jenaka. Sehingga bonek diharapkan dapat berkontribusi terhadap pembangunan karakter ABK beserta orang tuanya maupun berbagai pihak yang terkait. Karena - walaupun, sudah banyak upaya pemerintah terhadap ABK, namun mengingat permasalahan yang begitu kompleks, sehingga perlu partisipasi aktif warga, termasuk juga kolaborasi antara warga dengan berbagai pihak terkait. Dinamika mengangkat karakter bonek dalam solusi ABK guna kontribusinya terhadap pembangunan tata kota yang inklusif - dibahas dan termasuk juga saran-saran aksesibilitasnya.
\end{abstract}

Kata Kunci: Local Wisdom; Urban Design; Social Change; Inclusion

\begin{abstract}
This paper tries to apply local wisdom as not always related to the past or the order of indigenous peoples. Local wisdom should be able to exist today and become the identity of a modern (urban) community. Local wisdom is needed not only so that the community can survive the onslaught of foreign cultures, but also is expected to be able to solve various problems, including the problem of Children with Special Needs (ABK). Bonek - abbreviation of the word bondho reckless, the real meaning: only armed with determination (brave). But reckless is interpreted positively, namely as a belief in taking action, as long as fighting for the truth, must come into being. Therefore, bonek needs to be associated with unyielding character and especially when it is related to the history of the heroism of Surabaya, bonek is an egalitarian, solider, hardworking, but witty value. So bonek is expected to be able to contribute to the development of the ABK's character and its parents and various related parties. Because - although there has been a lot of government effort towards $A B K$, but given the problems that are so complex, it requires the active participation of citizens, including collaboration between citizens and various related parties. The dynamics of raising the bonek character of the ABK solution for its contribution to inclusive urban planning development - are discussed and include suggestions for accessibility.
\end{abstract}

Keywords: Local Wisdom; Urban Design; Social Change; Inclusion

(C) 2020 The Authors. Published by TALENTA Publisher Universitas Sumatera Utara

Selection and peer-review under responsibility of Seminar Nasional Kearifan Lokal V 2020

p-ISSN: 2654-7031, e-ISSN: 2654-704X, DOI: 10.32734/ee.v3i1.867 


\section{Kearifan Lokal dan Perubahan Sosial}

Kearifan lokal merupakan bagian dari budaya masyarakat yang diwariskan secara turun temurun melalui cerita dari mulut ke mulut yang diekspresikan dengan bahasa yang yang tak dapat dipisahkan dari bahasa masyarakat itu sendiri. Sedangkan perubahan sosial adalah perubahan cara hidup yang berbeda dari cara hidup yang sebelumnya diterima, karena adanya perubahan kondisi geografi, kebudayaan material, komposisi penduduk, ideologi maupun adanya difusi atau penemuan baru di masyarakat. Sehingga faktor penyebab perubahan sosial dapat karena faktor internal maupun eksternal seperti inovasi sosial.

Inisiasi inovasi sosial, perlu menggali kearifan lokal, terlebih dahulu, sehingga perubahan lingkungan "baru" tersebut diterima dengan mudah, karena sesuai dengan budaya atau nilai yang dianut. Artinya perlu digali kebiasaan, cara hidup, pola pikir (mindset), cara pandang atau persepsi dari suatu masyarakat yang menjadi sasaran, sehingga terjadi perubahan sosial yang bermakna atau paling tidak, tidak terjadi penolakan; seperti contoh berikut :

- Program Eliminasi kasus Tetanus Neonatorum (ETN) di Kalimantan. Bidan desa setempat yang mendapat mandat bahwa daerah kerjanya, terdapat kasus TN. Maka ia melakukan pengamatan mendalam mengenai kebiasaan perawatan bayi baru lahir masyarakat setempat sebelum program ETN berjalan. Ternyata masyarakat mempunyai kebiasaan memandikan bayi baru lahir selama sepekan dengan air sungai yang dipercaya sebagai air suci, dimana dahulu airnya jernih, sekarang karena adanya industrialisasi di sekitar sungai, air jadi keruh. Maka bersamaan program ETN tersebut, dilakukan penyuluhan dan sekaligus demo pembuatan proses penyaringan air.

- Program bantuan pembuatan jamban di masyarakat yang terbiasa melakukan mandi cuci kakus (MCK) di sungai. Sebaiknya tidak langsung dibangun jamban di setiap rumah, walaupun sebelumnya disetujui oleh pimpinan dan perwakilan warga setempat. Sosialisasi Perilaku Hidup Bersih Sehat (PHBS) perlu dilakukan dengan memasukkan pandangan hidup bersih sehat terlebih dahulu sebelum membuat jamban.

Kearifan lokal adalah nilai-nilai luhur yang berlaku dalam tata kehidupan masyarakat; atau juga gagasan setempat yang bijaksana dan diikuti oleh anggota masyarakat. Namun sayangnya, kearifan lokal jarang dikaitkan dengan masa kini maupun masyarakat modern atau perkotaan. Kepustakaan dan diskusi tentang kearifan lokal sering - hanya membahas kearifan lokal dengan masa lalu atau nilai-nilai yang masih hidup di desa atau masyarakat adat. Mengingat kecenderungan saat ini adalah globalisasi perkotaan, dimana desa terutama yang terletak di sekeliling sebuah kota mulai "mengubah diri" jadi kota, dengan adanya perluasan wilayah pemukiman atau perkantoran/pabrik. Gejala perubahan sosial di "kota baru" di desa pinggiran kota dapat dikatakan sebagai perubahan sosial yang kurang manusiawi. Suasana yang sebelumnya produktif dengan sedikit pengeluaran, kaya dengan kehidupan sosial dan spiritual menjadi kota yang dibangun berdasarkan kepuasan material belaka namun ternyata semu, karena ternyata meninggalkan masalah yang lebih pelik, seperti ketimpangan sosial dan kriminalitas. Disamping itu, hanya 80\% penduduk dunia ini yang mempunyai kearifan lokal, maka agar perubahan sosial terjadi dengan lebih manusiawi dan adaptif, adalah, dengan - salah satunya mengupayakan penggalian kearifan lokal di masing-masing daerah, agar terjadi lingkungan binaan yang berbudaya.

\section{Inklusi Sosial dan Tata Ruang}

Inklusi sosial adalah upaya mendorong seluruh elemen masyarakat, termasuk yang dikaruniai Anak Berkebutuhan Khusus (ABK) agar mendapat kesetaraan dan perlakuan yang bermartabat.

Definisi tentang ABK beragam, namun di sini, dipilih definisi yang berisi ajakan untuk deteksi dini dan harapan agar ABK dapat berkembang optimal. ABK adalah seseorang yang kurang dari 18 tahun atau lebih dari 18 tahun tetapi usia mental masih dibawah 18 tahun - mengalami masalah tumbuh kembang dan memerlukan layanan khusus, - namun bila orang tua/keluarga bersama warga sekitar menghargai selayaknya seorang anak, perkembangan mereka dapat optimal.

ABK secara sederhana, terbagi menjadi dua, yaitu fisik dan non fisik. ABK fisik dikonotasikan sebagai disabilitas yang terlihat langsung, misal buta, bisu tuli ataupun tuna daksa dan pemakai alat bantu/kursi roda, dll. Sedangkan ABK non fisik, misal ABK dengan masalah keterbatasan interaksi sosial karena autis atau ADHD/Attention Deficit and Hyperactive Disorder; ABK dengan keterbatasan komunikasi dan proses berpikir karena disabilitas intelektual atau Down Syndrome, dll. 
Keterbatasan ABK bukan penghalang untuk berkembang optimal, namun di negara sedang berkembang, dimana terdapat hambatan struktur atau sistem - kultur dan individu, menyebabkan permasalahan ABK menjadi kompleks. ABK yang hidup di kota dan terutama dari keluarga kurang mampu itu mendapatkan triple discrimination. Oleh karena itu, untuk memutus rantai setan kemiskinan dan ABK, Yayasan Peduli Kasih ABK, sebagai sebuah lembaga yang bekerja di masyarakat, menawarkan solusi sederhana yang merujuk pada rekomendasi badan kesehatan dunia, WHO bahwa model penyelesaian masalah ABK : sebagai pendekatan model sosial, bukan "hanya" model medikal. Pendekatan metode ini mendasarkan pada hukum Bronfenbenner dan sesuai International Classification of Functioning of Health and Disabilities (ICF).

Kompleksitas masalah ABK bermula dari struktur tubuh ABK sendiri, sebagaimana struktur tubuh manusia yang kompleks, saling berhubungan. Sebagai contoh Anak dengan Down Syndrome (ADS), jangan hanya dianggap karena kelainan kromosom, namun lihatlah secara holistik, yaitu tidak hanya karena kelainan genetik, namun juga sebagai manusia yang utuh, yang mempunyai kelebihan dan kekurangan masing-masing. Demikian pula dengan permasalahan otot ADS yang hipotoni atau kekenyalan otot kurang, dengan memperhatikan pula seluruh organ tubuh ADS ini, organorgan yang mempunyai otot yaitu : jantung (jantung lemah atau bocor), mata (strabismus atau juling), telinga (pendengaran kurang), atau bahkan otot pergerakan tubuh sendiri, yang menyebabkan cepat capai atau lemah.

Sistem yang melingkupi kompleksitas masalah ABK, termasuk juga sistem kesehatan nasional, dimana anggaran terbatas dan tenaga kesehatan terbatas yang disebabkan karena penyebaran tenaga yang tidak merata, kurang kompeten dan tidak mudah dijangkau.

Masalah kultur yang menyebabkan orang tua ABK terpuruk, karena malu, stigma - dianggap karma, dianggap penyakit menular, dianggap anak nakal, bahkan ABK dianggap tidak bisa diajari atau bodoh.

Masalah individu dalam ABK, umumnya berasal dari ketidak mampuan maupun ketidak mauan orang tua ABK, seperti kurang pendidikan, status sosial ekonomi rendah maupun pengetahuan/ketrampilan parenting. Status sos-ek rendah pun mempengaruhi kemampuan orang tua memberikan gizi yang cukup dan akses terhadap kesehatan (terapi), pendidikan (sekolah), maupun penyediaan alat bantu (assistive technology yang dibutuhkan seperti kursi roda).

Model penyelesaian masalah ABK, sesuai dengan rekomendasi ICF, ada tiga, yaitu perubahan struktur atau sistem,; diupayakan tetap aktif; dan partisipatif atau terlibat dalam kegiatan kemasyarakatan. Permasalahan keterbatasan ABK dapat diubah (atau diperbaiki) struktur tubuhnya melalui alat bantu (assistive device, seperti walker dan kursi roda) ataupun tindakan (seperti operasi/bedah). Disamping itu, agar supaya ABK dapat fungsional, membutuhkan sistem penanganan yang dapat menjamin akses dan penanganan yang tepat, karena permasalahan ABK umumnya membutuhkan jangka waktu lama penyelesaiannya dan intens. Struktur atau sistem yang akan dilakukan untuk solusi ABK tidak dapat hanya menggantungkan pada yang ahli, seperti model medikal, yang tentu saja membutuhkan biaya yang tidak sedikit. Oleh karena itu, disarankan bagi negara yang sedang berkembang, lebih baik difokuskan pada model sosial. Yaitu mengupayakan agar ABK supaya dapat tetap aktif dan berpartisipasi di masyarakat, seperti saling tolong menolong dengan pembentukan lingkungan yang inklusif.

Definisi tata ruang adalah wujud struktur ruang dan pola ruang. Yang disebut struktur ruang adalah susunan pusat pemukiman dengan jaringan sarana prasarana sebagai pendukung kehidupan sosial ekonomi masyarakat yang hirarkis dan fungsional. Sedangkan pola ruang adalah distribusi pemanfaatan ruang dalam suatu wilayah yang meliputi peruntukan ruang sesuai fungsinya sebagai perlindungan dan budi daya. Jadi tata ruang yang inklusif tidak saja pada pengaturan tata ruang (fisik) namun juga pembentukan suasana (yang ramah ABK atau inklusif). Pengaturan tata ruang kota yang inklusif pada ruang privat, seperti pada tempat pemukiman (misal perumahan, apartemen), maupun yang publik, seperti tempat belajar (misal sekolah, pondok pesantren, universitas), tempat berproduksi (misal kantor, pabrik, toko/mall), tempat rekreasi (misal bioskop, mall, tempat olahraga, gedung kesenian), tempat melakukan kegiatan keagamaan (misal gereja, masjid dll termasuk tempat pemakaman) dan tempat pembuangan sampah dll).

Upaya membentuk lingkungan yang inkusif, hendaknya menyeluruh dan terintegrasi, merujuk pada hukum Bronfenbenner, melalui lingkaran-lingkaran sosial yang dimulai dari lingkungan terdekat, yaitu orang tua dan keluarga, kemudian sekolah dan warga sekitar, yang pada akhirnya masyarakat luas. Maka penyediaan sarana prasarana bagi ABK ini juga dapat dipakai sebagai sarana hubungan interaksional yang terjadi antara lingkaran terdekat dari ABK yaitu orang tua dan keluarga, komunitas sampai masyarakat luas. Contoh, ramp, tidak hanya tersedia di jalan masuk sebuah gedung, namun juga menyeluruh. Antar ruang di dalam gedung tersebut ataupun antar gedung dan tempat parkir, termasuk juga fasilitas kamar mandi, tempat wudhu maupun tempat duduk yang ramah ABK, termasuk juga segi keamanannya. 
Sehingga tidak saja tersedia fasilitas, namun terbentuk juga suasana yang ramah ABK, bahkan ramah bagi semua orang, termasuk lansia yang juga rawan disabilitas.

Tata ruang perkotaan di negara sedang berkembang pada umumnya mengacu pada permasalahan urbanisasi, yang dikaitkan dengan kegagalan pembangunan. Berdasarkan kesejarahan, penduduk kota Indonesia, merupakan masyarakat yang spiritual, maka perlu diupayakan pembangunan karakter manusia urban dengan kehidupan yang lebih manusiawi. Konsep urban spirituality ini tentu berbeda dengan konsep pembangunan kota yang civil society ala Barat.

Untuk mewujudkan tata kota yang inklusif, perlu digali nilai-nilai luhur dan pengembangan moral yang sudah terinternalisasi serta tata ruang kota yang menjauhkan dari urban fabric morfologi kota yang materialistik diskriminatif.

\section{Kearifan Lokal Surabaya: Budaya Arek dan BONEK}

Surabaya sebagai kota terbesar di Indonesia, karena DKI Jakarta adalah propinsi -maka tak ada kota lain di Indonesia yang lebih besar dari Surabaya. Surabaya juga terkenal dengan sebutan kota pahlawan, terutama dengan kisah heroisme 10 Nopember.

Penggalian kearifan lokal Surabaya yang kekinian dan inklusif, hendaknya tidak mengacu pada perseorangan/individu pahlawan yang memang banyak dilahirkan di kota ini. Untuk itu, budaya arek (Suroboyo) dan bonek atau bondo nekat diangkat sebagai spirit inklusif.

Adrian Perkasa, dosen Sejarah Universitas Airlangga, berpendapat, budaya arek merupakan "pemberontakan pemuda" Surabaya dan sekitarnya (mulai dari Gresik, Sidoarjo, Surabaya, Mojokerto dan Malang), dari kekuasaan Mataraman. Sikap dendam membara dari arek Suroboyo melawan Mataraman meskipun akhirnya kalah pada tahun 1625, meninggalkan semangat pantang menyerah terhadap pengaruh Mataraman. Tata bahasa, penutup kepala maupun pembentukan karakter, merupakan simbol semangat sama rata, sama rasa, atau egaliter, solidaritas, demokrasi dari arek Suroboyo, yang berbeda dari Mataraman.

Perbedaan tata bahasa, tampak pada tidak ada perbedaan strata dalam berbahasa maupun istilah. Artinya tidak ada kromo inggil terhadap yang tua, atau kepada yang kasta atau sosial ekonominya lebih bagus. Demikian pula istilah arek yang ditujukan pada masyarakat umum, yaitu tidak saja untuk menyebut seorang anak, remaja, dewasa maupun lansia, namun semua (tua-muda, bangsawan/pejabat maupun rakyat jelata) dianggap setara, yaitu arek.

Penutup kepala Mataraman terkenal dengan blangkon yang mbendol mburi, beda dengan udeng Suroboyo yang rata, tidak ada yang timbul di belakang, yang sering dipakai pada aktor kesenian tradisional Surabaya, ludruk. Filosofi ini merujuk bahwa arek Suroboyo, bila berbicara blak-blak an atau tanpa tedeng aling-aling yang bermakna suka berterus terang, apa adanya, namun disampaikan dalam bentuk parikan (semacam pantun) yang terkesan jenaka. Beda dengan budaya Mataraman yang lebih senang bila tidak terlalu berani mengungkapkan pemikirannya, yang berakibat menggunjing atau membahas di belakang kita (mbendol mburi).

Arti harfiah bondo nekat atau disingkat jadi bonek, adalah berbekal hanya kenekatan (keberanian). Namun nekat yang positif yaitu sepanjang memperjuangkan kebenaran, bermakna keyakinan untuk pantang menyerah. Merujuk pada semangat kepahlawanan arek Suroboyo, maka bonek adalah : nilai egaliter, solider, pekerja keras namun jenaka.

\section{Pengembangan Kota Inklusif}

Undang-undang Penataan Ruang no 26/2007 telah memberikan kewenangan kepada pemerintah provinsi dan pemerintah kota/kabupaten untuk mengatur tata ruang yang sesuai dengan potensi budaya dan karakter warga. Bahkan sebelum pengetahuan modern terkait dengan penataan ruang berkembang pesat, sebenarnya masyarakat asli Indonesia sudah mengenal beberapa konsep modern penataan ruang kota.

Surabaya pada abad ke 16 sudah merupakan sebuah kadipaten yang telah menjalankan fungsi ideologis, administratif, politik, dan ekonomi secara dominan dibanding daerah lain di sekitarnya. Penataan tata kota Surabaya saat itu diperlakukan selayaknya sebuah organisme hidup sesuai pola kosmologi Jawa sehingga mencetak perkampungan dengan posisi yang disesuaikan berdasarkan fungsi serta aktifitas penduduk yang menghuninya. Inilah keunikan kampung Surabaya yang merupakan bagian penting dari eksistensi kota. 
Tolok ukur pembangunan kota inklusif adalah bilamana kebutuhan kelompok rentan sudah terpenuhi dan dengan melibatkan warga kelompok rentan tersebut, sesuai dengan jargon nothing about us without us. Merujuk pada issue Sustainable Development Goals yang tertuang dalam amanat UU Disabilitas no 8 tahun 2016, maka indikator kota inklusif adalah keterlibatan aktif dari ABK untuk mendapat hak dan akses; ABK mendapat perlakuan sikap yang sama dari warga lainnya; termasuk juga mendapat layanan yang informatif.

Sudah banyak pemerintah kota yang mendeklarasikan diri sebagai kota inklusif, saat ini belum ada kota yang benarbenar inklusif. Demikian pula, Surabaya sebagai satu-satunya kota di Indonesia yang mendapat apresiasi sebagai inisiasi kota layak anak kategori utama versi Kementrian Pemberdayaan Perempuan dan Perlindungan Anak, Surabaya, seperti belum ada data resmi jumlah ABK di masyarakat. Pemerintah kota Surabaya memang giat menfasilitasi sekolah pemerintah menjadi sekolah inklusif baik di berbagai jenjang pendidikan. Namun data keterlibatan ABK (dan orang tuanya) untuk mendapatkan hak dan akses yang setara, belum tersedia.

Data dari pengalaman Yayasan Peduli Kasih ABK (YPKABK) selama hampir 8 tahun mendorong para orang tua dan keluarga ABK terutama dari keluarga kurang mampu di Surabaya dan sekitarnya, adalah, orang tuanya mempunyai "mental miskin", overprotective, mempunyai harapan yang tidak realistis atau bahkan tidak mempunyai harapan terhadap ABK. Hal ini tidak sejalan dengan karakter bonek yang seharusnya sudah terinternalisasi dalam diri orang tua dan keluarga ABK.

Karakter bonek seharusnya menjadi inspirasi bagi pembangunan kota inklusif Surabaya. Tidak saja bagaimana orang tua dan keluarga ABK memberlakukan ABK dengan karakter bonek; namun juga bagaimana sekolah, warga sekitar dan masyarakat umum dapat berinteraksi, menghargai dan membantu ABK agar optimal dengan karakter bonek. Demikian juga bagaimana pemerintah kota Surabaya dengan karakter bonek, membina semua elemen masyarakat, baik secara individu maupun golongan, untuk berperan serta dan kolaborasi demi tata ruang inklusif tercapai. Pemerintah kota Surabaya juga hendaknya dengan karakter bonek dapat merencanakan, memanfaatkan dan mengevaluasi fasilitas ramah $\mathrm{ABK}$, melalui cara-cara kreatif dan pantang menyerah.

\section{Kontribusi BONEK dalam Pembangunan Karakter ABK}

Permasalahan ABK di Surabaya begitu kompleks sehingga diperlukan perubahan sosial yang mempertimbangkan pembangunan karakter arek berkebutuhan khusus Suroboyo yang bonek. Untuk itu, tahapan Awareness, Interest, Evaluation, Trial, Accept, Adopt, Advocacy (AIETAAA), dikaitkan dengan karakter egaliter, solider, pekerja keras dan jenaka dapat diinternalisasi dalam diri semua yang terlibat dalam pengasuhan ABK ---- melalui bagaimana orang tua keluarga dengan ABK, guru dan terapi, serta masyarakat luas memberlakukan ABK dengan karakter bonek (mulai di rumah, sekolah/tempat terapi, dan di masyarakat dengan memprioritaskan Attitude terlebih dahulu, baru Skill dan Knowledge. Untuk itu perlu diperhatikan makna perilaku ABK sehingga dapat diberikan perlakuan yang tepat. Makna perilaku ABK adalah : meminta sesuatu, meminta perhatian, menghindar tugas atau otomatis. Jadi para pihak yang berada di sekitar ABK perlu mengetahui apa isyarat dari perilaku yang ditunjukkan ABK, saat ia fase tenang maupun tantrum (marah yang tanpa sebab). Respons yang tepat dari perilaku yang ditunjukkan ABK dapat menjadi konsekuens (akibat) dari perilakunya (Hukum ABC, Antecedents, Behavior, Consequence), tampak di tabel penanganan di kolom orang tua dan keluarga, atau disebut lingkaran sosial pertama dari hukum Bronfenbenner. Demikian pula bagaimana guru dan terapis serta warga sekitar memberlakukan ABK dengan karakter bonek di lingkungan terdekatnya (sekolah, tempat terapi dan komunitas), tampak pada kolom sekolah dan komunitas. Termasuk pula bagaimana masyarakat umum berinteraksi, mendukung dan membantu ABK dan keluarganya dengan karakter bonek di lingkaran sosial ke tiga. 
Tabel 1. Tahapan sosialisasi lingkungan rumah ABK

\begin{tabular}{|c|c|c|c|c|}
\hline \multirow{2}{*}{$\begin{array}{l}\text { Tahapa } \\
\text { n }\end{array}$} & \multirow{2}{*}{$\begin{array}{l}\text { Perlakuan terhadap ABK } \\
\text { dengan karakter bonek }\end{array}$} & \multicolumn{3}{|l|}{ Penanganan yang dilakukan : } \\
\hline & & Orang tua dan keluarga & $\begin{array}{l}\text { Sekolah dan masyarakat } \\
\text { kampung sekitar }\end{array}$ & Masyarakat luas \\
\hline $\begin{array}{l}\text { Awaren } \\
\text { ess }\end{array}$ & $\begin{array}{l}\text { Melakukan berbagai cara } \\
\text { kreatif pendekatan awal } \\
\text { dengan orang tua ABK, } \\
\text { masyarakat sekitar, } \\
\text { swasta, pemerintah, } \\
\text { organisasi masyarakat }\end{array}$ & $\begin{array}{l}\text { Mengadakan edukasi dan } \\
\text { deteksi dini tumbuh kembang } \\
\text { anak } \\
\text { Mengadakan seminar } \\
\text { parenting }\end{array}$ & $\begin{array}{l}\text { Mengadakan edukasi dan } \\
\text { konsultasi pada warga } \\
\text { sekolah dan warga } \\
\text { kampung }\end{array}$ & $\begin{array}{l}\text { Melakukan edukasi baik } \\
\text { on line dan off line } \\
\text { termasuk internet, radio } \\
\text { maupun parenting on line }\end{array}$ \\
\hline Interest & $\begin{array}{l}\text { Melakukan pendekatan } \\
\text { sehingga orang tertarik } \\
\text { dengan issue ABK }\end{array}$ & $\begin{array}{l}\text { Memberi beasiswa pada } \\
\text { orang tua ABK yang } \\
\text { berkomitmen } \\
\text { mengoptimalkan anaknya. }\end{array}$ & $\begin{array}{l}\text { Mensosialisaikan materi } \\
\text { dan media tentang cara- } \\
\text { cara berkomunikasi } \\
\text { dengan ABK yang } \\
\text { praktis melalui flyer, } \\
\text { newsletter }\end{array}$ & $\begin{array}{l}\text { Mensosialisaikan materi } \\
\text { dan media tentang cara- } \\
\text { cara berkomunikasi } \\
\text { dengan ABK yang } \\
\text { praktis melalui radio, } \\
\text { koran, TV }\end{array}$ \\
\hline $\begin{array}{l}\text { Evaluat } \\
\text { ion }\end{array}$ & $\begin{array}{l}\text { Mengajak para pihak } \\
\text { untuk mencoba menilai } \\
\text { sendiri manfaat inklusi }\end{array}$ & $\begin{array}{l}\text { Meminta menuliskan } \\
\text { pengalaman membersamai } \\
\text { anak dalam buku harian dan } \\
\text { memberi penilaian sendiri } \\
\text { secara kualitatif }\end{array}$ & $\begin{array}{l}\text { Mengedukasi dengan } \\
\text { memberikan contoh } \\
\text { lingkungan ramah ABK } \\
\text { di tempat/negara lain, } \\
\text { sehingga dapat gambaran } \\
\text { jelas }\end{array}$ & $\begin{array}{l}\text { Mengedukasi dengan } \\
\text { memberikan contoh } \\
\text { lingkungan ramah ABK } \\
\text { di tempat/negara lain, } \\
\text { sehingga dapat gambaran } \\
\text { jelas }\end{array}$ \\
\hline Trial & $\begin{array}{l}\text { Mendorong para pihak } \\
\text { untuk mencoba kegiatan } \\
\text { inklusi yang paling } \\
\text { mungkin dikerjakan }\end{array}$ & $\begin{array}{l}\text { Mendorong secara santun } \\
\text { agar mempertimbangkan dan } \\
\text { mencoba sendiri serta } \\
\text { menilai tingkat keBISAan } \\
\text { untuk menjadi potensi } \\
\text { dengan cerita kepahlawanan } \\
\text { bonek }\end{array}$ & $\begin{array}{l}\text { Mendorong gerakan } \\
\text { literasi, seni dan olah } \\
\text { tubuh sebagai media } \\
\text { inklusi sosial }\end{array}$ & $\begin{array}{l}\text { Mendorong gerakan } \\
\text { literasi, seni dan olah } \\
\text { tubuh dengan membuat } \\
\text { festival persahabatan }\end{array}$ \\
\hline Accept & $\begin{array}{l}\text { Mendorong para pihak } \\
\text { untuk menerima ABK } \\
\text { sebagai anggota keluarga, } \\
\text { apapun kondisinya }\end{array}$ & $\begin{array}{l}\text { Menggali kekuatan dan } \\
\text { kelemahan anak dan lebih } \\
\text { menfokuskan pada kekuatan } \\
\text { dan keBISAannya untuk } \\
\text { menjadi potensi }\end{array}$ & $\begin{array}{l}\text { Menghargai karya dan } \\
\text { mendorong untuk berbuat } \\
\text { lebih baik }\end{array}$ & $\begin{array}{l}\text { Menghargai karya dan } \\
\text { mendorong untuk berbuat } \\
\text { lebih baik }\end{array}$ \\
\hline Adopt & $\begin{array}{l}\text { Mendorong para pihak } \\
\text { untuk menginternalisasi } \\
\text { nilai-nilai inklusivitas } \\
\text { sosial }\end{array}$ & $\begin{array}{l}\text { Membantu terjadinya proses } \\
\text { transformasi nilai bonek dan } \\
\text { mewujud dalam karakter } \\
\text { pantang menyerah }\end{array}$ & $\begin{array}{l}\text { Membantu terjadinya } \\
\text { proses transformasi nilai } \\
\text { bonek dan mewujud } \\
\text { dalam karakter pantang } \\
\text { menyerah }\end{array}$ & $\begin{array}{l}\text { Membantu terjadinya } \\
\text { proses transformasi nilai } \\
\text { bonek dan mewujud } \\
\text { dalam karakter pantang } \\
\text { menyerah }\end{array}$ \\
\hline $\begin{array}{l}\text { Advoca } \\
\text { te }\end{array}$ & $\begin{array}{l}\text { Mendorong para pihak } \\
\text { untuk meyakinkan secara } \\
\text { kreatif spirit bonek untuk } \\
\text { inklusi sosial }\end{array}$ & $\begin{array}{l}\text { Gelar karya seni, literasi, } \\
\text { olah tubuh dan mengemas } \\
\text { secara kreatif sebagai media } \\
\text { advokasi untuk mendapat } \\
\text { perhatian lebih luas. }\end{array}$ & $\begin{array}{l}\text { Menghargai karya } \\
\text { literasi, seni dan } \\
\text { olahtubuh; ikut berperan } \\
\text { dalam kegiatan misalnya } \\
\text { storytelling dan drama } \\
\text { inklusif karakter bonek, }\end{array}$ & $\begin{array}{l}\text { Menghargai karya } \\
\text { literasi, seni dan } \\
\text { olahtubuh; ikut berperan } \\
\text { misalnya dalam kegiatan } \\
\text { storytelling dan drama } \\
\text { inklusif, semangat bonek }\end{array}$ \\
\hline
\end{tabular}

Berikut dinamika proses mengangkat kearifan lokal bonek dalam pembentukan karakter ABK :

Orang tua dan keluarga dari ABK, yang menjadi lingkaran sosial pertama, hendaknya mempunyai karakter keyakinan pantang menyerah dalam menghadapi berbagai kendala atau keterbatasan yang ada. Orang tua harus yakin bahwa tidak ada anak yang bodoh, yang ada adalah orang dewasa yang kurang dapat memahami dan membersamai ABK. Cara-cara kreatif perlu dicari agar ABK dapat mengejar masalah tumbuh kembangnya, melatih kemandirian melalui activity daily living dan mengoptimalkan potensinya. Karena setiap orang selalu mempunyai kekuatan dan kelemahan masing-masing. 
Bagaimana orang tua dan keluarga menggali kegiatan yang disukai anak - hobi - minat atau apa yang masih bisa dilakukan oleh ABK. Memang tidak semudah membalik tangan, namun bila sudah diniatkan dan dilakukan terus menerus dan kreatif, maka ABK bersama orang tua dan keluarga dapat melatih dan menjadikan sebagai kekuatan potensi ABK. Peran pemerintah dalam pembinaan ABK diperlukan dengan pembangunan fasilitas umum yang ramah ABK seperti tempat bermain, yang juga dapat berkolaborasi dengan pihak swasta. Demikian pula pemerintah dapat mengadakan penyuluhan deteksi dini di masyarakat dan termasuk juga pelatihan tenaga terkait layanan ABK tentang deteksi dini.

Lingkaran sosial ke dua dari ABK adalah sekolah dan masyarakat kampung terdekat, termasuk pandangan tokoh masyarakat. Berdasarkan hasil penelitian yang telah dilakukan YPKABK pada tahun 2017, menunjukkan 83\% masyarakat mengetahui istilah $\mathrm{ABK}$ namun bila ditanyakan lebih lanjut tentang jenisnya, umumnya hanya bisa menjawab bahwa ABK adalah autis. 67\% dari warga masyarakat ingin menolong orang tua atau keluarga abk dan disabilitas, namun tidak tahu cara menolongnya, bahkan cenderung takut bila orang tua tersebut tersinggung. Sehingga perlu diciptakan ruang komunikasi yang lebih intens, baik di tingkat grass root (masyarakat), maupun antar guru-terapiorang tua, bahkan antar pemerintah dan swasta dalam menciptakan tata ruang yang inklusif.

Lingkaran sosial ke tiga dari ABK adalah masyarakat luas. Dari hasil penelitian YPKABK, warga yang pernah mendengar tentang istilah ABK dan disabilitas, 67\% berusia kurang dari 40 tahun, dan hanya 13\% yang berusia lebih dari 50 tahun. Sebanyak 45\% warga berusia lebih dari 40 tahun tidak pernah mendengar istilah ABK dan disabilitas, serta cenderung tidak peduli, karena dirinya sendiri juga punya masalah kesehatan juga. $67 \%$ petugas kelurahan, kecamatan dan tokoh masyarakat menyatakan siap (ingin) membantu ABK dan disabilitas, namun ketika ditanyakan lebih lanjut, mereka enggan, bahkan dikatakan anggarannya tak ada ataupun pada waktu penyusunan anggaran atau disebut musyawarah kerja tingkat kecamatan, tidak diijinkan untuk ikut menyuarakan kepentingan dan kebutuhan ABK dan disabilitas ini. Diperlukan juga pelatihan pada ABK yang sudah trampil literasi, agar dapat menyuarakan langsung apa yang dialaminya.

Hasil pelaksanaan kegiatan didapatkan orang tua dan keluarga mulai terbentuk kerjasama baik dengan yayasan, maupun para pihak di sekitarnya, termasuk sekolah dan tempat terapi maupun komunitas. Namun mengingat begitu kompleks permasalahan ABK, sampai dengan saat ini masih terus dilakukan kerja sama agar terbentuk trust dan kerjasama yang lebih intens sehingga karakter bonek lebih terinternalisasi.

\section{Kontribusi BONEK dalam Pembanunan Tata Ruang Inklusif}

Tata ruang yang inklusif dapat terbentuk dengan partisipasi aktif warga atau masyarakat luas dan kolaborasi, untuk itu Yayasan Peduli Kasih ABK mengupayakan bagaimana mengajak semua pihak dapat berpartisipasi aktif dan berkolaborasi dengan karakter bonek untuk menciptakan tata ruang yang inklusif.

Berbekal kolaborasi dengan bisnis (perusahaan dimana yayasan menjadi target CSR/Corporate Social Responsibility, yaitu Telkom), pemerintah (kecamatan dimana yayasan berada termasuk puskesmas dan pendidikan), praktisi dan akademisi (dokter, psikolog, guru, arsitek dll), organisasi (PKK, HIMPSI/Himpunan Psikolog Indonesia, IDI/Ikatan Dokter Indonesia), maupun media dan pemerhati anak), yayasan Peduli Kasih ABK selama tahun 2016-2018 melakukan sosialisasi perwujudan mengangkat bonek melalui terbentuknya tata ruang yang inklusif atau ramah ABK dengan tahapan perencanaan, pemanfaatan dan pengevaluasian.

Berikut dinamika proses mengangkat kearifan lokal bonek dalam pembentukan tata ruang inklusif, tahap perencanaan : pendekatan kepada pamong atau pemegang kebijakan, dalam hal ini kecamatan, puskesmas dan satuan pendidikan di tingkat kecamatan.

Tahap pemanfaatan :

- Melakukan parents support group, penguatan orang tua ABK dengan diskusi non formal kepada para orang tua ABK dan disabilitas, baik di rumah mereka atau di manapun yang mereka nyaman.

- Membuat afterschool programme untuk ABK dan disabilitas sesuai keBISAan berdasarkan assessment sederhana. 
- Berkolaborasi dengan banyak pihak, baik lintas sektor maupun lintas pihak untuk dapat memberikan konseling keluarga tentang pembentukan karakter bonek. Sedikit tantangan dari orang tua, yang khawatir stigma bonek yang dianggap perusuh.

- Melakukan survey atau penelitian sederhana untuk mengetahui need and demand analysis kepada semua lingkaran sosial yang terkait.

- Mengadakan penyuluhan, edukasi, pemutaran film kepedulian terhadap ABK dan disabilitas maupun bedah buku karya ABK dan disabilitas.

- Melakukan bisnis sosial (menjual hasil karya ABK dan disabilitas; pelatihan berbayar bagi guru dan terapis ABK dan disabilitas; edutrip istimewa berupa travel inspiratif dan kunjungan meluaskan wawasan inklusif) agar yayasan mandiri dan sustained.

Tahap evaluasi : didapatkan perlu kerja bersama terutama advocacy dengan pemerintahan dan swasta

\section{Kesimpulan dan Saran}

Kearifan lokal arek Suroboyo dijadikan sebagai semangat inklusif dalam rangka menuju lingkungan yang ramah ABK. Bonek dapat diterapkan sebagai upaya penyelesaian masalah kekinian, untuk itu perlu tahapan yang menyeluruh dan berkolaborasi dengan banyak pihak.

\section{Referensi}

[1] Departemen Pendidikan dan Kebudayaan RI, 1995. Konsep tata ruang suku bangsa dayak kenyah di Kalimantan Timur, Jakarta.

[2] Hadiati, SR et al, 2019. Empowering program as a special service for the poor of children with special needs, Indonesian Journal of Disability Studies, 6 (2): 223-229.

[3] Kristiyanto, EN, 2017. Kedudukan kearifan lokal dan peranan masyarakat dalam penataan ruang di daerah, Jurnal Rechtsvinding, 6 (2): 151 171

[4] Muhaimin, 2016. Kedudukan kearifan lokal dalam penataan ruang provinsi Bali, Jurnal Penelitian Hukum De Jure, 740: 59-71.

[5] Soetomo, S, 2002. Dari Urbanisasi ke morfologi kota, Badan Penerbit Universitas Diponegoro, Semarang

[6] Uchild, CU, 2005. Making possibilities visible : the process of collaboration between general and special education teachers in an inclusive early childhood education program, graduate school the Ohio State University 